\title{
Designing a nutrition-based intervention using a novel cooperative learning model
}

\author{
R. Breach ${ }^{1}$, C. Arbuthnott ${ }^{1}$, V. Stilwell ${ }^{1}$, S. McLaren ${ }^{1}$, G. Leith ${ }^{1}$, H. Cargill ${ }^{2}$ and M. R. Ritchie ${ }^{1,3}$ \\ ${ }^{1}$ Arbroath High School, Arbroath, Angus, UK, ${ }^{2}$ Dundee College, Dundee, UK and ${ }^{3}$ Napier University, Edinburgh, UK
}

Up to $80 \%$ of cancers of the breast, bowel and prostate may be preventable by diet ${ }^{(1)}$, yet despite numerous health education initiatives ${ }^{(2)}$ a recent survey has reported a high percentage of children eat sweets and chocolate once daily or more ${ }^{(3)}$.

Cooperative learning (CL) is a novel method of education that focuses on integration of multiple methods of interaction and cooperation. Five basic elements constitute CL: positive interdependence; face-to-face interaction; individual accountability; social skills; group processing. The CL approach involves group work and it has been shown to assist with retention of information and improve interest in the subject matter ${ }^{(4)}$.

The aim of the present study was to use an example of $\mathrm{CL}^{(5)}$ which involved group work where groups were set structured tasks with identifiable outcomes as a basis for the intervention promoting healthy eating. The intervention was part of the Angus Learning Festival with the theme 'health', a local council educational initiative in which parents and pupils were invited to participate in a 'healthy eating' workshop at Arbroath High School in Angus. The workshop included four work stations. Pupils and parents were paired and several pairs worked on the work station for 10 min before moving on to the next work station. Work-station tasks were completed by discussion within the pair and within the group. All groups completed all four work stations.

Work-station tasks included the following activities. Work station 1 involved identification of herbs. Twelve samples of common medicinal and culinary herbs including lavender, peppermint, thyme, rosemary, marjoram, ginger, fennel, chamomile and eucalyptus were presented as growing herbs, essential oils or in root form such as ginger. Group tasks involved identification of each herb by smell and sight and a subsequent listing of their uses on a report form issued to each group. Participation in work station 2 involved analysis of a fast-food (McDonald's) menu in order to assess the intake of fat, sugar, salt and energy from specific food items and drinks as a percentage of the guideline daily amounts. Participants used an enlarged copy of a menu which detailed nutrient information and \% GDA for each food item. Each group was provided with a record sheet on which they identified a breakfast, lunch, dessert item and drink and subsequently listed the total intake of saturated fat, energy, salt and sugar for the four items. The task was completed by suggesting methods which could make the items 'healthier'. At work station 3 participants identified foods contained in 'touchy-feely' boxes. The box number was recorded against a suggested food item on a record sheet. Foods used in the identification experiment included hot dog sausages, gherkins, onions, peas, sweetcorn, grapes, tomatoes, pears, apples and peaches. At work station 4 participants designed, named and created a healthy dessert using soya-based yoghurts and soya desserts including caramel, chocolate and caramel flavours provided by Alpro UK and a variety of fresh fruit. Participants used booklets produced by Alpro and the British Heart Foundation promoting the use of fresh fruit and plant based diets in order to help design the dessert that had a health promoting function. The desserts were created, named and displayed before being judged. This was a practical exercise where samples of fresh fruits such as cherries, grapes, apples, oranges, pears, bananas and peaches were used to decorate the desserts. The best dessert was awarded a prize. Information leaflets provided by the British Heart Foundation, Lamberts Healthcare, Bioforce UK, Solgar UK and Alpro UK containing information relevant for the purpose of each task were used by participants. Junior pupils (age 11-15 years) created resources such as the 'touchy-feely' boxes, posters detailing each workshop and workcards for the event, senior pupils (age range 16-18 years) assisted with setting up and running work stations.

On finishing all work station tasks participants were invited to complete an evaluation form ${ }^{(6)}$. Forms prepared by senior pupils were modified versions of a pre-existing evaluation form. Completed forms were analysed and the impact of the intervention on participants' awareness of healthy eating and the feasibility of changing to a healthier diet were assessed ${ }^{(6)}$.

The success of CL being used as a model for this intervention demonstrates the importance of the environmental effects on student's motivation for learning. The combined contribution from fellow pupils, parents and staff provided a pleasant, meaningful and successful learning climate.

The study was supported by Bioforce UK, Lamberts UK, Solgar UK, Alpro UK and Arbroath High School Parent Teacher Association.

1. Cummings JH \& Bingham SA (1998) Br Med J 317, 1636-1640.

2. Expert Panel on School Meals (2003) Hungry for success - a whole school approach to school meals in Scotland www.scotland.gov.uk/library5/ education/hfs-00.asp

3. MacLeod F (2008) Diet - a social divide that starts aged two. news.scotsman.com/latestnews/-Diet-a-social.3790156.jp

4. Johnson DW \& Johnson RT (1989) Cooperation and Competition: Theory and Research. Edina, MN: Interaction Book Company.

5. Gillies RM (2004) Learn Instruct 14, 197-213.

6. McNulty J, Pritchard A, Doyle A et al. (2009) Proc Nutr Soc 68, E97. 